\title{
ФИЛОСОФИЯ
}

\author{
УДК 379.852/ (4)
}

DOI: $10.21779 / 2500-1930-2017-32-97-103$

\section{Д.А. Гусенова}

\section{Метаморфозы путешествия в европейской познавательной культуре}

Дагестанский государственный университет; Россия, 367001, г. Махачкала, ул. М. Гаджиева, 43a; gusenowa03111978@yandex.ru

В статье на основе сравнительно-исторического метода автор показывает, что, несмотря на различие в формах и видах в целом, путешествие носило в большей степени познавательный характер, нежели рекреационный. Ещё в Библии идея познания мира становится основополагающей и в последующем с распространением христианства гармонично вплетается в европейскую культуру. В Библии описано, как первые люди были изгнаны из рая, чтобы они могли постичь все многообразие бытия через созерцание добра и зла. Этот результат сделанного человеком эпохального выбора предопределили всю последующую историю. Путешествие как элемент познавательной европейской культуры отчётливо отображается и в так называемых «философских турах» первых античных философов, которые посещали отдалённые уголки континента в поиске истины, новых знаний, самообразования. Путешествия с познавательной целью совершались и в последующие периоды. Это и эпоха Великих географических открытий (XV-XVII вв.), и познавательное путешествие в новое время, получившее название Grand Tour, которое с XVIII в. становится элементом престижа и показателем личного благосостояния. С конца XIX века начинается институционализация путешествия, трансформация его в туризм, требующий работы целого ряда специалистов: историков, археологов, этнографов, маркетологов, экскурсоводов и др. Начиная с этого периода вплоть до наших дней перемещения в пространстве становятся более комфортными и многообразными, «погружение» различные эпохи более реалистичным, а ландшафт Земли - более узнаваемым.

Ключевые слова: путешествие, туризм, образование, европейская культура.

На различных этапах развития общества у людей были самые разные мотивы для перемещения в пространстве, влияющие на содержание и формы путешествия. Со сменой эпох, как подметил И.В. Зорин, менялось наше представление о путешествии, подчинённое пространству и времени, а также исторически обусловленному вектору прохождения маршрутов [6, с. 12]. Есть также предположение, что смена «места обитания человека» была обусловлена «развитием производительных сил (собирательство, земледелие, животноводство и т. д.) ...» [15, с. 43] или же сформировавшимся оседлым образом жизни, ибо «чтобы осознать себя путешествующим (путешественником), человек должен ощутить себя живущим на одном месте» [1, с. 81].

Размышляя о метаморфозах путешествия в процессе развития европейской познавательной культуры, нельзя обойти стороной её главную основу - христианство. Обратим внимание, что первое библейское путешествие - изгнание Адама и Евы из рая связано с совершённым грехопадением - вкушением запретных плодов с древа познания. Было сказано: «а от древа познания добра и зла не ешь, ибо в день, в который ты вкусишь от него, смертью умрешь» [Быт. 2:17]. После вкушения запретного плода у человека открылись познавательные способности, актуализированные через представления о добре и зле, о моральном и аморальном, о справедливом и несправедливом. 
После изгнания Адаму и Еве представилась возможность сравнить райскую жизнь, наполненную благоденствием, с другой стороной мироздания. Из библейских мифов известно, что их путь пролегал по пустынной и безжизненной земле, совсем не похожей на рай, который они знали, в котором «произрастил Господь Бог из земли всякое дерево, приятное на вид и хорошее для пищи, ...всех животных полевых и всех птиц небесных».

В целом в Библии путешествие предстаёт как вынужденное странствие и как новая веха в истории человечества. Примечателен пример Каина, который огорчается невниманием к своим стараниям во время подношения даров Всевышнему. На это обращает внимание Всевышний, упрекая в неискренности во время жертвоприношения и отсутствии любви к Господу, а значит - греховности: «Поникло лице твое? Если делаешь доброе, то не поднимаешь ли лица? А если не делаешь доброго, то у дверей грех лежит» [Быт. 4:2-4]. Как известно, ослеплённый ревностью Каин совершает второй грех - братоубийство, который открывает доселе не виданную человеку смерть - печальное осознание конечности жизненного пути, а также боль утраты материнского сердца. Познав конечность своей жизни, осознав её хрупкость, Каин обращается к Богу: «Наказание мое больше, нежели снести можно; и вот, Ты теперь сгоняешь меня с лица земли, и от лица Твоего я скроюсь, и буду изгнанником и скитальцем на земле; и всякий, кто встретится со мною, убьет меня» [Быт. 4:13-14]. Как известно, Каин вынужден был отправиться в долгое странствие и поселиться на «земле Нод, на восток от Эдема» [Быт. $4: 16]$.

В античный период путешествия становятся «частью общественной жизни». Они были связаны с политическими интересами, торговлей, паломничеством и образованием [8, с. 105]. Благодаря путешествиям развивались философия и наука. В пример можно привести античных философов Фалеса Милетского, посетившего жрецов из Фив и Мемфиса в Египте, Пифагора, побывавшего на Крите, знаменитого греческого историка Геродота, написавшего в путешествии свою знаменитую «Историю», в которой он подробно рассказывает обо всем увиденном и услышанном им в Вавилоне, Северном Причерноморье, на Балканском полуострове и т. д. Это и знаменитый Сократ, побывавший в Дельфах, Истме, Сицилии, куда также трижды ездил и Евклид, в последующем основавший в Александрии математическую школу. Ксенофан почти всю жизнь путешествовал по городам Древней Греции и южной Италии, в последующем поселился в Элее, где создал философское учение элейцев. Платон с научной целью вместе с соратниками ездил в Мегары, Кирену, Италию, Египет, в результате чего была пополнена его библиотека в Академии. Прославившись за пределами Афин, он сам стал объектом духовного паломничества. По Элладе путешествовали Диоген и Аристотель. Аристотель посетил и Среднюю Азию, чтобы получить новые знания. И.А. Кирсанова отметила, что если греки путешествовали с какой-то конкретной целью (деловой, политической, религиозной, познавательной), то после усиления Римского государства римляне путешествовали преимущественно с рекреационными целями: «для удовольствия и развлечения, стремились к максимальному комфорту» [8, с. 106]. Особый интерес вызывали у римских путешественников «Чудеса света»: египетские пирамиды, Колосс на острове Родос, храм Артемиды в Эфесе.

В период Средневековья с укреплением позиций церкви путешествия всё чаще совершаются с религиозными и образовательными целями. Подобные «образовательные путешествия» продолжались весь средневековый период. Яркий представитель эпохи Ф. Аквинский в поисках знаний прошел через Альпы, Бургундию, далее посетил 
Париж, а затем, преодолев еще 300 миль, Кельн. Августин Блаженный в возрасте 16 лет ездил учиться в Карфаген.

В Новое время путешествия, называемые Grand Tour (1660-1840 гг.), совершались привилегированными слоями населения для ознакомления с культурным наследием и предметами искусства Античности и эпохи Возрождения через континентальную Европу, а со второй половины XVIII в. - и по Южной и Северной Америке. В России эти процессы тормозились крепостным правом, юридически «привязавшим к земле» нижние слои населения, а высшее сословие свободно стало путешествовать лишь после принятия «Манифеста о вольности дворянской» (1762), по которому дворяне получали право выезда за границу, но «по требованию правительства должны были возвращаться в Россию» [4, с. 43]. Среди причин, которые, по мнению В.К. Егорова, ещё препятствовали путешествиям, называются «войны в Европе, на Кавказе, в Крыму, крайне сложный процесс освоения приобретенных территорий», а также верноподданническая национальная психология [4, с. 43]. Уже с XIX века, в период «затишья», начинается активное перемещение россиян на Запад, Восток, Юг и в Святые земли. Т.В. Паликовой упоминается семимесячное путешествие цесаревича по Евразии Николая Александровича (1890-1891 гг.), посетившего Австро-Венгрию, Грецию, Индию, Цейлон, Сингапур, Яву, Сиам, Китай и Японию». Далее путь пролегал по Сибири через Хабаровск и Урал в Санкт-Петербург. Схожие маршруты проходил в 1837 году и цесаревич Александр, наследник Николая I, а также великий князь Алексей - четвёртый сын Александра II. Т.В. Паликова называет подобные ознакомительные путешествия по стране «важным пунктом программы воспитания будущего императора» [11, с. 4]. Автор подмечает, что, если предыдущие наследники российского престола устремились на Запад, то, начиная с цесаревича Николая Александровича, предпринимаются походы и к восточным рубежам, для демонстрации военной мощи России на Дальнем Востоке [11, c. 4]. Однако именно европейский Grand Tour был зафиксирован как исторический и социальный феномен.

Самый распространенный маршрут Grand Tour начинался с Дувра (Англия), далее с различными целями посещались Нидерланды, Бельгия, Франция. В Париж ехали, чтобы совершенствоваться во французском языке, осваивать культуру, придворные нравы, моду парижского высшего общества, обучаться танцам, фехтованию, верховной езде, что было необходимо для унаследовавших высокие титулы и позиции в обществе. Далее путешественники направлялись в Женеву (колыбель Реформации) или Лозанну. Оттуда зачастую в сопровождении многочисленных слуг и франкоговорящего гида через Альпы, где на относительно небольшом пространстве размещено огромное количество памятников раннего периода христианства, эпохи Возрождения и Барокко, всемирно известные шедевры изобразительного искусства, скульптуры, архитектуры, археологии, музыки и т. д., путешественники обычно возвращались на север в немецкоговорящую Европу: в Инсбрук, Вену, Дрезден, Берлин и Потсдам, Мюнхен, Гейдельберг, далее в Голландию и прославившуюся своими галереями Фландрию, прежде чем вернуться через Ла-Манш в Англию. C XVII века по этим местам путешествовали и молодые художники, чтобы совершенствоваться в своём ремесле.

C XVIII века Grand Tour начинает приобретать современные очертания. Возможность совершить его показателем личного благосостояния. Путешественники возвращались с книгами, картинами, скульптурами, которые затем выставлялись в частных коллекциях, галереях, гостиных, чтобы подчеркнуть собственный статус. В таких путешествиях происходили первые контакты разных культур. Примером этому является идея, выдвинутая Г. Гессе, о феномене «паломничества в страну Востока» или по ана- 
логии с ней «паломничество в страну Запада» Скороходовой Т.Г. как «интеллектуальное, духовное и реальное перемещение в пространство западной культуры для понимания её ценностей, норм и наследия, а также открытия самих себя» [15, с. 164]. Для бенгальских реформаторов и деятелей культуры, в частности просветителя Раммохана Райа (1772-1833), императивом поездки выступали собственный интеллектуальный рост и развитие своей страны. В своём «Автобиографическом письме» просветитель от «чувства огромного отвращения к установлению британской власти в Индии» после общения с европейцами и знакомства с их законами и системами управления эволюционировал к мнению, что, «хотя их правление и является иностранным игом, оно должно скорее и намного вернее привести к улучшению жизни местного населения» [18, с. 497]. Первую такую поездку он совершил в 1831 г., чтобы воочию увидеть цивилизацию, представители которой пришли в Индию. В последующем он и его соратники посвятили свою жизнь приобщению индийского общества к научным и культурным достижениям Европы, призывая к распространению светского образования.

Идеи просвещения и романтизма индивидуализируют область путешествий - всё более популярными становятся экскурсии, которые становятся самостоятельным инструментом познания. Через экскурсию путешественнику открылась привлекательность моря, гор, сельских ландшафтов, античных развалин. Она усилила межкультурные связи и коммуникации [6, с. 12]. М.А. Захарищева и Л.А. Власова подметили, что в России ещё в «Уставе народным училищам» 1786 года «содержалась рекомендация по организации учебных экскурсий». А школьный Устав 1804 г. рекомендовал «прогулки на природу, в ремесленные мастерские» [5, с. 47].

В России ввиду её больших территорий путешествия использовались и в качестве инструмента администрирования. Интересным примером такого путешествия является последующая за реформой местного самоуправления (1775 г.) поездка Императрицы Екатерины II в мае-июне 1780 г. по пяти губерниям в сопровождении «26 персон, среди них 24 государственных чиновника разного уровня, ...высшие должностные лица соответствующих губерний, по территории которых она проезжала» [13, с. 5]. Инспекционная поездка Екатерины II, которая в последующем стала традицией дома Романовых, сопровождалась изучением работы «приказов общественного призрения и состояния экономики, а также ...раздачей дополнительных пожалований на школы, дома призрения, возведение каменных домов для горожан и на другие цели» [13, с. 5].

Эпоха Возрождения и успехи научной революции открыли новую страницу путешествий - эпоху Великих географических открытий и последовавших за этим геополитических сдвигов, растянувшихся, по мнению Л.Л. Рыбаковского [14, с. 44], вплоть до Первой мировой войны. Это были экспедиции первых смельчаков, для которых регулярные поездки становились частью их профессиональной деятельности: торговофинансовой, военной или научно-исследовательской. Речь идёт об Испании, Португалии, а позднее Великобритания с Францией, которые после усиления Османской империи осваивали новые маршруты в Китай и Индию. Кроме того, зарождавшийся в этот период капиталистический уклад требовал увеличения прибавочной стоимости за счёт колонизации других народов, их порой поголовного истребления, а также возрождения рабства $[15$, с. 44]. В знаменитой работе К. Маркса и Ф. Энгельса «Манифест Коммунистической партии» по этому поводу отмечается: «Крупная промышленность создала всемирный рынок, подготовленный открытием Америки. Всемирный рынок вызвал колоссальное развитие торговли, мореплавания и средств сухопутного сообщения...» [9]. Потребность в постоянно увеличивающемся рынке сбыта продукции гнала буржуазию по всему земному шару, делая производство и потребление всех стран космополитиче- 
ским. На смену старой местной и национальной замкнутости и существованию за счет продуктов собственного производства приходит всесторонняя связь и всесторонняя зависимость наций друг от друга.

Дальнейшая метаморфоза путешествия связана с социально-экономическими процессами, техническими достижениями и развитием транспортной инфраструктуры. Туризм начал формироваться в последней трети XIX века и был связан с именем английского пастора Томаса Кука и его первым экскурсионным железнодорожным туром, организованным в 1843 г. [10, с. 217], а также с созданным в 1856 г. туристическим агентством Томаса Кука. В этот период путешествие приобретает черты туризма в современном его понимании. Сам по себе туризм стал возможным также благодаря утверждению социального фактора, выраженного, по мнению В.К. Егорова, в виде гарантий свободы перемещения, в т. ч. за рубеж, появления усовершенствованных видов транспорта и развитой транспортной инфраструктуры и наличия свободных капиталов у желающих заняться таким неприбыльным делом, как путешествия [4, с. 42].

Открытие в 1869 г. Суэцкого канала упростило коммуникацию между отдалёнными территориями Евразии, а после установления британского протектората важнейшей туристической дестинацией стал Египет. Проанализировав заметки о путешествиях французов, побывавших в Северной Африке в последней трети XIX века, посвящённые «колониальной эпопее», Е.Н. Моисеева подметила, что «зарождающийся массовый туризм воспринимался современниками (возможно, не всеми) довольно негативно» [10, с. 217]. Упрощение способов путешествия лишило человека романтики, ощущения первооткрывателя, приключения, но при этом «освободило» от многочисленной «свиты», сделав само путешествие индивидуально переживаемым опытом.

Наряду с географической мобильностью, вызванной профессиональными потребностями в развитии торговых и деловых связей, достижении политических соглашений о снятии таможенных ограничений и т. д., важнейшим условием для путешествий стало наличие свободного времени. Такое перемещение путешествий в сферу досуга ознаменовалось появлением туризма как социального института, первоначально элитарного, а со второй половины XX века доступного широким слоям населения. Научнотехнические достижения значительно расширили границы возможного для человека, способствуя быстрому накоплению средств, которые он мог тратить на появившееся вследствие автоматизации труда свободное время. Как справедливо подмечает по этому поводу А.В. Карпов, «многое, что питает туризм, объясняется феноменом скрытой безработицы» [7, с. 1]. Индустриализация экономики, переместив трудовые ресурсы в сферу услуг, сделав рабочий график более гибким, а выходные дни более продолжительными, позволила более часто покидать место постоянного проживания и отправляться в путешествие. В этот период путешествие развивается уже как «индустрия туризма» $[6$, с. 12], ставящая «на поток» возможности удовлетворения потребности в приключениях. С этого момента, и здесь мы согласимся с А.В. Карповым, «понятие путешественника сильно девальвировано». В предыдущие эпохи путешествие, коммерческого ли характера, политического, духовного или какого-то иного содержания, было связано с риском для жизни, и действия пилигримов не вызывали массового повторения - во всех случаях путешествие «воспринималось или как тяжкая необходимость, или как сомнительное предприятие по зову беспокойного сердца» [7, с. 1].

С институционализацией путешествия, трансформацией его в туризм, благодаря работе целого ряда специалистов (историков, археологов, этнографов, маркетологов, экскурсоводов и др.) перемещения в пространстве становятся более комфортными и многообразными, «погружение» во времени - более реалистичным, а ландшафт Земли 
- более узнаваемым. К примеру, изобретение в 50-х годах XX века реактивного и турбовинтового самолетов позволило СССР значительно увеличить пассажиропоток иностранцев, заинтересовавшихся нашей страной после первого полёта человека в космос [12, с. 248]. А популярный на Ближнем Востоке дайвинг получил развитие благодаря изобретению акваланга, барокамеры и других принадлежностей. Он включает в себя обучение, организацию, продажу оборудования и сам дайв-туризм.

Для специальных видов туризма сегодня уже недостаточно простого стремления познать что-то новое, «необходимы высокая физическая, специальная техническая, психологическая и теоретическая подготовка, требующая специальных знаний, без которых любое мероприятие обречено на неудачу и даже опасно для здоровья и жизни его участников» [3, с. 34]. При этом научно-технические достижения сами становятся объектом туристического интереса. Е.Ш. Танеева выводит совокупную долю делового и научного туризма в Московской области (2010-2011 гг.) в 15 и 14 \% соответственно, которая по объёму уступает лишь оздоровительному (20-19\%) и кратковременному массовому (23-25\%) туризму [16, с. 128]. Среди объектов такой специфической аттракции называются: Орбитальная станция «Алмаз» (г. Реутов); образцы крылатых ракет реутовского «НПО машиностроения» (г. Реутов); радиотелескоп ДКР-1000 меридианного типа (г. Пущино) и др. Таким образом, мы можем утверждать, что туризм имеет воспитательный и педагогический потенциал. По мнению М.С. Топчиева и В.С. Дрягалова, страны превратились «в глобальный парк развлечений, в которых открываются границы, упрощается визовый режим, строятся гостиницы по международным стандартам, завозятся универсальные фастфуды и напитки, предназначенные только для туристов» [17, с. 263].

Таким образом, в историческом ракурсе путешествие, несмотря на формы и виды осуществления, в целом сохраняло за собой статус важнейшего элемента или даже методологии познавательной европейской культуры.

\section{Литература}

1. Беккер И.Л. Путешествие как способ социального бытия и становления личности // Известия ПГПУ. Сер.: Общественные науки. - 2006. - № 2 (6) - С. 80-86.

2. Беккер И.Л. Социальный, культурный и духовный смысл путешествия как способа самопознания и бытия человека // Известия ПГПУ им. В.Г. Белинского. -2009. - № 11 (15). - С. 7-11.

3. Булашев А.Я. Прикладной и познавательный аспекты спортивного туризма // Слобожанський науково-спортивний вісник. - 2015. - № 1 (45). - С. 34-37.

4. Егоров B.K. Феномен туризма // Экономические и социальные перемены: факты, тенденции, прогноз. - 2009. - № 1 (5). - С. 40-44.

5. Захарищева М.А., Власова Л.А. Образовательное путешествие в системе высшего образования // Вестник Удмуртского университета. - 2012. - Вып. 2. - С. 45-48.

6. Зорин И.В. Путешествие как феномен и феноменология путешествий // Вестник РМАТ. - 2011 - № 1 (1). - С. 10-13.

7. Карпов A.B. Анализ паттерна путешествия в современной культуре // Аналитика культурологии. - 2008. - № 12. - С. 24-28.

8. Кирсанова И.А. Путешествие как способ познания чужеземной культуры в эпоху Античности // Наука и современность. - 2011. - С. 105-109.

9. Маркс K., Энгельс $\Phi$. Манифест Коммунистической партии: www.marxists.org/russkij/marx/1848/manifesto.htm. 
10. Моисеева E.H. Организованный туризм и самостоятельные путешествия в последней трети XIX века: французы в Северной Африке // Вестник СГТУ. - 2013. № 2 (70). - Вып. 1. - С. 217-220.

11. Паликова T.B. Путешествие на Восток цесаревича Николая // Вестник Бурятского государственного университета. - 2013. - № 7. - С. 4-7.

12. Pannonopm A.B. Туризм на реактивной тяге // Мир транспорта. - 2014. - № 5. - C. 246-253.

13. Репортаж из прошлого. Путешествие Императрицы Екатерины II 1780 г. / публикация и коммент. В.Н. Лещикова // Псков. - 2013. - № 39. - С. 5-22.

14. Рыбаковский Л.Л. Мировые миграции населения в геополитических координатах // Народонаселение. - 2015. - № 4. - С. 43-57.

15. Скороходова Т.Г. Паломничество в страну Запада» в опыте мыслителей Бенгальского Ренессанса // Вопросы философии. - 2011. - № 11. - С. 163-173.

16. Танеева Е.Ш. Перспективы развития научного туризма в Московской области // Сервис в России и за рубежом. - 2014. - Т. 8, № 5. - С. 127-135.

17. Топчиев М.С., Дрягалов В.С. «Человек путешествующий» и индустрия туризма // Каспийский регион: политика, экономика, культура. - 2012. - № 3. C. 262-267.

18. Collet S.D. The Life and Letters of Raja Rammohun Roy / Ed. by D.K. Biswas and R.Ch. Ganguli. $3^{\text {rd }}$ ed. - Calcutta, 1962. - P. 497.

UDC 379.852/ (4)

Поступила в редакцию 22 февраля 2017 г.

DOI: $10.21779 / 2500-1930-2017-32-97-103$

Travel metamorphoses in the European informative culture

\section{D.A. Gusenova}

Dagestan State University; Russia, 367001, Makhachkala, M. Gadzhiev st., 43a; gusenowa03111978@yandex.ru

The article shows that despite the difference in forms and types overall, travel has been educational in nature rather than recreational. The research is made on the basis of the comparativehistorical method. The idea of knowledge of the world is fundamental in the Bible and subsequently, with the spread of Christianity is harmoniously interwoven into European culture. The Bible describes how the first humans were expelled from the Paradise, so they could understand the diversity of life through the contemplation of good and evil. This result is man-made landmark choice determined by the subsequent history. Travel, as the cognitive element of the European culture is clearly displayed in the so-called "philosophical rounds" of the first ancient philosophers, who visited the remotest corners of the continent in search of the truth, new knowledge, self-education. Travel for education purposes was also made in subsequent periods. This is the era of Great geographical discoveries (XV-XVII centuries) and informative travelling into a new time, called the Grand Tour, which from the eighteenth century becomes an element of prestige and an indicator of personal well-being. Since the end of XIX century the institutionalization of travel, its transformation into tourism begins that requires a number of specialists: historians, archaeologists, ethnographers, marketers, tour guides, etc. From this period up to the present days, movement in space has become more comfortable and diverse, "immersion" in time is more realistic and the landscape of the Earth is more recognizable.

Keywords: travel, tourism, education, European culture.

Received 22 February, 2017 